\title{
Discussion about the Influence of Western Painting Teaching on the Fine Arts in the Qing Dynasty
}

\author{
He Yang \\ Huanghe Science and Technology College \\ Zhengzhou, China
}

\begin{abstract}
Since the introduction of western painting in China in the Ming Dynasty, Chinese painting has been influenced by western painting. In the Qing Dynasty, a group of Western missionary painters which are represented by the Italian missionary Castiglione came to China. They not only brought Western painting techniques but also were appointed by the Chinese emperors as imperial painters in the royal court. On the one hand, in order to cater to the aesthetic taste of the ruling class, they started to learn Chinese traditional painting techniques; on the other hand, under the Chinese emperor's instruction, they taught Chinese people the Western painting techniques. Thus a new painting style of combining Chinese and Western paintings formed in their royal court paintings and western painting teaching, which had a far-reaching influence on Chinese art and art education.
\end{abstract}

Keywords-Castiglione, integration of Chinese and Western, Western painting

\section{INTRODUCTION}

Western painting was introduced to China from the Wanli period of the Ming Dynasty, and in the seventh year of Wanli period of the Ming Dynasty (AD 1579) Italian Catholic missionary Luo Mingjian came to China, brought a typical Western painting hand-painted icon. In the $23^{\text {rd }}$ year of Wanli period of the Ming Dynasty (AD 1595), Italian missionary Matteo Ricci came to China, brought a wealth of art works including paintings and sculptures, and in the $28^{\text {th }}$ year of Wanli period of the Ming Dynasty (AD 1600) he paid tribute to Emperor Shenzong with the drawings "God Portrait" and "Mother of God". In the second of Chongzhen period of the Ming Dynasty (AD 1629), Italian missionary Francesco Sambiaso (1582-1649) wrote a treatise to explain Western painting techniques to Chinese people, called "Painting Answers", but with little effect.

When it comes to the influence of Western painting on Chinese traditional fine arts and art education, one has to talk about, that is Castiglione. Giuseppe Castiglione (1688-1766) from Milan Italy, Catholic missionary, painter, came to Beijing to present himself to Emperor Kangxi in the $54^{\text {th }}$ year of Kangxi period (AD 1751), and then he stayed in the royal court as imperial painter for fifty-one years through the three imperial periods of Kangxi, Yongzheng and Qianlong till he died of illness. Castiglione was the earliest western painter in came to China who had received the most rigorous training in western painting, who had the highest skill in painting, who was the most favored imperial painter in court by the ruling class of Qing Dynasty. He not only taught in the court directly, trained about 20 disciples, but also in the long-term art activities, he made a wide range of effects on Chinese court art In addition to Castiglione, there were some other foreign missionaries who are skilled in Western painting techniques such as French missionary Jean Denis Attiret, Bohemia missionary Inatius Sichelbarth, French missionary Louis De Poirot, Italian missionary Joannes Damascenus Salusti also recognized by the Chinese high-level ruling class.

In the three imperial periods of Kangxi, Yongzheng, Qianlong, the society was stable and economy was prosperous, missionary painters who was proficient in Western painting gathered in Chinese court, which created a good condition for the mutual integration and development of Western painting and Chinese traditional painting, and also formed the special education mechanism in Qing Dynasty painting courtyard that mutual exchange and learning of Chinese and Western painting. However, the Chinese ruling class did not fully accept the expression method of Western painting, they are more in love with the traditional Chinese painting concept, which makes these Western painters had to make some changes.

\section{The INFLUENCE OF TRADITIONAL CHINESE PAINTING TECHNIQUES ON WESTERN PAINTING}

In the "Yanjing Kaijiaolue", it is written: "Although Denis (ie Wang Zhicheng) has fine painting skills, but the Emperor (Qianlong) likes Chinese style specially like landscape painting, Denis can not achieve his best. The emperor told Gongbu (the Board of Works): the landscape painting has deep and far interests and suitable in everywhere, Denis' oil painting is fine, but unfortunately oil painting is not satisfied me, if let him study landscape painting, he will be able to be the best. So I ordered him to learn landscape painting skills. As for photo art, he can use oil painting, let him know my order." The Emperor Kangxi in the previous requested Castiglione to learn the meaning of Chinese painting. Thus it can be seen that the high-level ruling class of China' although appreciated the realistic ability of Western painting techniques but not fully recognized. As a result, the Western painting painters working in court began to meet the traditional aesthetic concept of Qing Dynasty emperor and the aesthetic requirements of Confucian culture, combined the Chinese painting techniques together with oil painting techniques and formed a unique style of 
painting. Western portraits focus on the expression of the light and darkness relationship of character's face, while the traditional techniques of Chinese painting focus on the inherent structure of the face. In order to meet the needs of traditional Chinese aesthetic concepts and court decoration, the court Western artists adopted many compromises to achieve the effect of Chinese and Western integration, such like: The characters use Western techniques, the background use Chinese techniques, or even background painted by Chinese painting techniques. Facial modeling use front light source to reduce the difference in brightness, meticulous depicting, symmetrical blooming to avoid the effect of yin and yang face. Western missionary painters in painting style are mainly with Western painting techniques, add to traditional Chinese painting techniques, to strengthen the realism of the painting, and strive to pursue the unity of form and spirit. They through the perspective and shading and light painting flexibility to adapt to the demands of Qing Dynasty's gorgeous color, elegant style and subtle implication, then formed a kind of new court painting style which is different from the previous court painting, but also different from the literati painting and folk painting at that time.

The painting "Bai Jun Tu" was painted by Castiglione in the $6^{\text {th }}$ year of Yongzheng period (AD 1728), it is a representative work which combined Chinese traditional painting techniques and Western painting light and shade perspective techniques together in one, which fully reflected the aesthetic taste of Chinese and Western integration. In the "Bai Jun Tu", Castiglione painted a hundred various shapes, high spirit horses with traditional painting materials of Chinese painting. In the picture he widely used Western painting focus perspective, light and shade methods to analyze the anatomy structure and modeling feature of the image, and made an accurate and realistic description for the structure and expressions of characters and horses. For the ink outline of pine needle, bark and grass leaves, the brush of stones and soil slope, the blending of horses and tree trunk, he still used traditional Chinese methods to paint, strengthen the application of lines in modeling, even the shade expressions of horses and tree trunks were also complete with traditional Chinese rendering methods. The whole picture uses the normal Western landscape painting's perspective techniques which near big and far small, near solid and far virtual, so that made the screen of a variety of images has clear primary and secondary layers, with harmonious rhythm and all blend into a whole, resulting in a quiet and far-reaching conception.

\section{ThE INFLUENCE OF WESTERN PAINTING TECHNIQUES ON CHINESE TRADITIONAL PAINTERS}

Since the introduction of European paintings by Ricci and other missionaries into China, Chinese painters were more or less influenced by Western painting techniques, and this influence was significantly strengthened in the Qing Dynasty, especially after Castiglione became the imperial painter in court, Chinese traditional painting began to draw on Western painting techniques.

Since Castiglione enter the royal court, Emperor Kangxi' ordered him taught the basic techniques and perspective technique of Western painting to Chinese painter Zhang
Weibang, Lin Chaokai and more than a dozen of "Bai Tang A" such as Fo Yan, Cha Shiba, Fu Hong, Wang Wenzhi, Quan Bao, Fu Lata, San Dali, Banda Lisha, Ba Shi, Sun Weifeng, Wang Jie, Ge Shu, Yong Tai and so on. In the first year of Yongzheng period, Banda Lisha, Ba Shi, Sun Weifeng, Wang Jie, Ge Shu, Yong Tai six people continued to stay with Castiglione to study, learning "line painting" and served as his assistants. The "Juanqinzhai Tongjinghua" which painted by his student Wang Youxue has fine brushwork, huge painting screen, and added the focus perspective and high-light shade Western painting techniques in the picture, makes people feel immersive, with strong sense of reality, there is a clear style of Chinese and Western painting techniques blending. In addition, according to the Qing court painting activities recorded in "Qing File": "at Yingtai Baoyue building, ordered Castiglione and other painters to paint with Western-style wall painting techniques according to Meiyue Xuan style". Also it wrote: "Ordered Wang Youxue to paint two paintings with line painting method respectively at the two sides of throne inside Yan Chun Ge and on the west wall inside the northern gate". Also wrote:" Ordered Ai Qiming to correct the line painting of the line painting on the south wall of Yang Xin Temple, and paint another white silk painting". This shows the painting activities of Castiglione and his assistants, students Wang Youxue and other court painters, which plays an important demonstration role for the "line method" teaching.

During Castiglione's imperial painter career, in addition to his disciples, he had co-painted with Tang Dai, Gao Qipei, Chen Mei, Shen Yuan, Yao Wenhan, Jin Kun, Cheng Zhidao, Li Huilin, Zhou Kun, Yu Sheng, Ai Qimeng, Fang Cong, Jin Tingbiao, Zhang Tingyan and other important painters. In this kind of cooperation, Chinese and Western painting styles and painting techniques are mutual influenced, promoted the development of the new painting style which is represented by Castiglione and integrated Chinese and Western painting together. At the same time there are many court painters such as Jiao Bingzhen, Leng Mei, Ding Guanpeng and others, mainly use Chinese painting techniques but pay more attention to light and shade effect, their paintings are more realistic, also formed a new style.

Jiao Bingzhen was good at character, landscape and construction painting. His painting style does not rigidly adhere to Chinese traditional painting techniques, but boldly absorbed the perspective techniques of western painting. He applies the principles of geometry, perspective and light and shadow into the creation of Chinese painting and formed his unique style which places the character into a real environment to form a clear bright and dark separation and lifelike image. In contrast to Castiglione's painting style which emphasis on color changes and three-dimensional representations of objects, Jiao Bingzhen only used western painting techniques in background painting, focusing on light and darkness rendering and near and far perspective, so that to make objects have three-dimension effect and depth-like feeling. He created a new style in meticulous re-color painting technique, but the key character portrayal he still used traditional Chinese painting techniques. In his paintings "Geng Zhi $\mathrm{Tu}^{\mathrm{N}}$ and "Lichao Xianhou Gushi Tu", we can see his kind of background with bright and dark changes and a strong sense of 
depth, and his character images with Chinese traditional painting artistic conception. "History of Qing Dynasty" recorded Jiao Pingzhen that "he was good at character and building painting, he knew the calculation and measurement, he used Western painting techniques, ... ... From far view, people, animals, flowers, houses are all stand vertical but with round shapes". Qing Shengzu Kangxi appreciated his painting level very much, once he greatly praised Jiao Bingzhen's paintings that: "Jiao Bingzhen always followed the degree of the seven starts and the distance of human body, so among the mountain peaks can still tell the near and far. It is more than painting brushes he held in hand, so wrote it down to remember".

"Summer Resort" is a masterpiece of Jiao Bingzhen's disciple Leng Mei. The whole painting overlooked the back garden of Summer Palace and the surrounding mountains from aerial view. The scenery is bright and clear, color setting is elegant and refreshing, concise and lively. The mountains and trees in the picture used Chinese traditional painting performance techniques, or brushed with dry pen, or rendered with green color. As for the performance of buildings, he not only used the Chinese boundary painting techniques, but also focused perspective skills in the composition, very meticulous brushwork. This picture reflects the inheritance of Leng Mei for Jiao Bingzhen's painting style and also a model work of the fusion of Chinese and Western painting techniques.

\section{CONCLUSION}

Western classicism, realism and Chinese traditional painting made further integration under the recognition of Western painting teaching by the high-level ruling class of China. Western missionary painters and their disciples integrated Chinese and Western painting techniques, compromised Chinese and Western aesthetic taste, drawn a large number of paintings for Chinese royal family in this new painting style. Qing Dynasty's Western painting teaching has become an integral part of the Chinese art and art education, which imported fresh blood for Chinese art and art education, also it guided Qing Dynasty court painting toward to a rational Chinese and Western integration.

\section{REFERENCES}

[1] Li Yonglin. [M]. History of ancient Chinese fine arts education. Nanning: Guangxi Fine Arts Publishing Company.2002

[2] Li Qiwen. [M]. The contact of China and European culture in Eighteenth Century. Beijing: Commercial Press .1962

[3] Wang Bomin. [M]. General history of Chinese painting. Beijing: Sanlian bookstore .2000

[4] Teaching and research sector of Chinese art history,Department of Art history, China Central Academy of Fine Arts [M]. Brief History of Chinese Fine Arts. Beijing: China Youth Publishing Company.2002

[5] Su Liwen. [M]. East-West Fine Arts Exchange. Nanjing: Jiangsu Fine Arts Publishing Company. 1998

[6] Zhang Guogang. [M] Ming and Qing Missionaries and European Sinology: Beijing: China Social Sciences Publishing Company .2001 